\title{
Does cytochrome P450 liver isoenzyme induction increase the risk of liver toxicity after paracetamol overdose?
}

This article was published in the following Dove Press journal:

Open Access Emergency Medicine

12 October 2011

Number of times this article has been viewed

\author{
Sarbjeet S Kalsi ${ }^{1,2}$ \\ David MWood ${ }^{2-4}$ \\ W Stephen Waring 5 \\ Paul I Dargan ${ }^{2-4}$ \\ 'Emergency Department, ${ }^{2}$ Clinical \\ Toxicology, Guy's and St Thomas' \\ NHS Foundation Trust, London; \\ ${ }^{3}$ King's Health Partners, \\ ${ }^{4}$ King's College London, London; \\ ${ }^{5}$ York Teaching Hospital NHS \\ Foundation Trust, York, UK
}

\begin{abstract}
Paracetamol (acetaminophen, N-acetyl-p-aminophenol, 4-hydroxyacetanilide) is the most common cause of acute liver failure in developed countries. There are a number of factors which potentially impact on the risk of an individual developing hepatotoxicity following an acute paracetamol overdose. These include the dose of paracetamol ingested, time to presentation, decreased liver glutathione, and induction of cytochrome P450 (CYP) isoenzymes responsible for the metabolism of paracetamol to its toxic metabolite N-acetylp-benzoquinoneimine (NAPQI). In this paper, we review the currently published literature to determine whether induction of relevant CYP isoenzymes is a risk factor for hepatotoxicity in patients with acute paracetamol overdose. Animal and human in vitro studies have shown that the CYP isoenzyme responsible for the majority of human biotransformation of paracetamol to NAPQI is CYP2E1 at both therapeutic and toxic doses of paracetamol. Current UK treatment guidelines suggest that patients who use a number of drugs therapeutically should be treated as "high-risk" after paracetamol overdose. However, based on our review of the available literature, it appears that the only drugs for which there is evidence of the potential for an increased risk of hepatotoxicity associated with paracetamol overdose are phenobarbital, primidone, isoniazid, and perhaps St John's wort. There is no evidence that other drugs often quoted as increasing risk, such as carbamazepine, phenytoin, primidone, rifampicin, rifabutin, efavirenz, or nevirapine, should be considered risk factors for hepatotoxicity in patients presenting with acute paracetamol overdose.
\end{abstract}

Keywords: paracetamol, overdose, hepatotoxicity, isoenzymes

\section{Background}

Paracetamol (acetaminophen, N-acetyl-p-aminophenol, 4-hydroxyacetanilide) overdose causing fatal hepatotoxicity was first reported in humans in 1966. ${ }^{1,2}$ Since then, paracetamol poisoning has become the most common cause of acute liver failure in many developed countries/regions, including the UK, US, Canada, Australia, and Scandinavia. ${ }^{3-7}$ Paracetamol poisoning may result from either an acute overdose (where the drug is ingested at a single point in time, usually within one hour), or as a staggered supratherapeutic ingestion over a longer period. This article will focus on single-ingestion paracetamol poisoning.

A number of factors are important in determining the risk of toxicity after paracetamol poisoning, and these influence the decision to administer antidotal treatment with $\mathrm{N}$-acetylcysteine. ${ }^{8-13}$ The plasma paracetamol concentration plotted against time after ingestion is compared with a "treatment line" to determine the need for antidotal therapy. There are a number of different treatment lines used around
Correspondence: David Wood Medical Toxicology Office, Bermondsey Wing, Guy's Hospital, Great Maze Pond, London, SEI 9RT, United Kingdom

Tel +442071885848

Fax +44 $207 \mid 88$ I289

Email david.wood@gstt.nhs.uk
Open Access Emergency Medicine 201 I:3 69-76

(C) 201 I Kalsi et al, publisher and licensee Dove Medical Press Ltd. This is an Open Access article

Dovepress

http://dx.doi.org/10.21 47//OAEM.S24962 which permits unrestricted noncommercial use, provided the original work is properly cited. 
the world. ${ }^{11-13}$ In addition, in the UK, there are currently two treatment lines, ie, one for those deemed to be at usual risk of paracetamol-related hepatotoxicity, and a lower line used for those deemed to be at "high" risk of paracetamol-related hepatotoxicity. ${ }^{9,13,14}$ Common factors used to determine risk of paracetamol-related hepatotoxicity include depletion of liver glutathione (eg, malnutrition, eating disorders) and induction of liver cytochrome P450 (CYP) 2E1 (eg, chronic ethanol use, phenytoin, or other enzyme-inducing drugs). In the UK, the process of determining which treatment line to base treatment on following a single-time point paracetamol overdose is known as "risk stratification". This relies on both laboratory measurement of paracetamol concentration and assessment of the patient history to determine the interval after ingestion, which appears to be reasonably reliable in this patient population. ${ }^{15,16}$ In addition to determining the need for treatment, clinicians need to consider the potential for adverse reactions to the antidote.

\section{Mechanism of paracetamol-related hepatotoxicity}

The parent paracetamol molecule is not in itself associated with toxicity. ${ }^{17}$ At therapeutic doses, paracetamol is predominantly metabolized by hepatic sulfation and glucuronidation, with less than 5\%-10\% being metabolized by the hepatic CYP system (predominantly CYP2E1 and CYP3A4) to $\mathrm{N}$-acetyl- $p$-benzoquinoneimine (NAPQI), a highly reactive intermediate metabolite responsible for paracetamol-related hepatotoxicity. ${ }^{18-20}$ At therapeutic doses of paracetamol, this metabolite is effectively detoxified by reduced glutathione into cysteine and mercapturic conjugates which are renally excreted. ${ }^{21}$ Following a supratherapeutic dose or overdose of paracetamol, glucuronidation/sulfation conjugation pathways are saturated, and therefore a greater proportion of paracetamol is metabolized to NAPQI. ${ }^{22-24}$ Intrahepatic glutathione stores may be insufficient to detoxify the greater NAPQI, and when glutathione concentrations fall to approximately $30 \%$ of normal, NAPQI covalently binds to hepatic cells. ${ }^{21}$ This is associated with irreversible hepatocellular necrosis which, in severe cases, results in liver transplant or death. ${ }^{14}$

\section{Definition of paracetamol-related hepatotoxicity}

Paracetamol-induced hepatotoxicity is classically defined as an aspartate aminotransferase or alanine aminotransferase rise to over $1000 \mathrm{IU} / \mathrm{L} .^{25,26}$ Patients without an aminotransferase elevation do not go on to experience acute liver injury and therefore are not at risk of acute liver failure or death. ${ }^{27,28}$ An aspartate aminotransferase or alanine aminotransferase exceeding $1000 \mathrm{IU} / \mathrm{L}$ is generally associated with histological changes of centrilobular necrosis of varying severity. ${ }^{29,30}$ However, for most patients, these changes are fully reversible, leading to recovery without any long-term damage..$^{29,30}$

Based on data from patients presenting with paracetamol poisoning prior to the introduction of antidotal therapy, Prescott reported that up to $25 \%$ of those with severe aminotransferase-defined hepatotoxicity died. ${ }^{31}$ This means that even without $\mathrm{N}$-acetylcysteine, more than $75 \%$ of severely poisoned patients will recover fully. Therefore, although aspartate aminotransferase or alanine aminotransferase are used to define paracetamol-related hepatotoxicity, a combination of International Normalised Ratio (INR), plasma creatinine, metabolic acidosis, and clinical factors, such as the presence of encephalopathy, are more reliable at selecting patients who will either die or require hepatic transplantation..$^{32,33}$

\section{Factors reported to be associated with increased risk}

There are a number of factors which potentially impact on the risk of an individual developing hepatotoxicity following an acute paracetamol overdose. These can be broadly divided into the following categories: dose of paracetamol ingested; time from ingestion to treatment with $\mathrm{N}$-acetylcysteine; increased metabolism of paracetamol to NAPQI due to induction of the relevant CYP isoenzymes; and reduction in liver glutathione stores. In this paper, we will review the evidence for increased risk of hepatotoxicity following paracetamol overdose due to CYP isoenzyme induction unrelated to ethanol.

\section{Evidence for induction of CYP isoenzyme system}

As discussed in the introduction, the toxic metabolite of paracetamol is NAPQI, and this is formed by oxidative metabolism via the CYP system. ${ }^{17-20,34}$ This system is subdivided into multiple isoenzyme groups with different substrate specificity. Animal studies in the 1970s demonstrated that paracetamol is metabolized by the CYP system. ${ }^{17,18}$ More recent investigations have centered on which isoenzyme(s) metabolize paracetamol, and the CYP1A2, CYP2A6, CYP2D6, CYP2E1, and CYP3A4 isoenzymes have all been investigated. ${ }^{35-43}$ The published literature is largely based on in vitro and animal models, with very few human studies in vivo. We will now summarize the available literature on the relative importance of these isoenzymes for paracetamol metabolism. 


\section{CYPIA2}

An in vitro study of IgG-mediated inhibition of CYP1A2 and CYP2E1 suggested that CYP1A2 contributed 30\%-56\% of metabolism, compared with the $30 \%-78 \%$ performed by CYP2E1. ${ }^{38}$ Unlike CYP2A6 and CYP2E1, inhibition of CYP1A2 and CYP3A4 in another in vitro study failed to reduce the production of NAPQI. ${ }^{44} \mathrm{~A}$ mouse model subsequently suggested that, unlike CYP2E1, CYP1A2 activity increased after higher doses of paracetamol. ${ }^{40}$ Double knockout mice for both CYP1A2 and CYP2E1 were protected against paracetamol-induced hepatotoxicity and glutathione depletion after massive overdose. However, the significance of these findings in animal studies is unclear, because human volunteer studies suggest that CYP1A2 inducers do not increase production of NAPQI after therapeutic doses of paracetamol. ${ }^{41}$

\section{CYP2A6}

CYP2A6 seems to oxidize paracetamol preferentially to 3-OH-acetaminophen, which is a nontoxic metabolite in a 3:1 ratio to NAPQI. ${ }^{35}$ Inhibition of human CYP2A6 in vitro reduces the amount of NAPQI produced. ${ }^{44}$ Therefore, from a toxicological perspective, it is unlikely that CYP2A6 plays an important role in paracetamol-related hepatotoxicity.

\section{CYP2D6}

In vitro, human CYP2D6 is one-third as efficient as CYP2E1, with a $4 \%-22 \%$ contribution to paracetamol metabolism, especially at higher paracetamol doses ${ }^{42}$ This observation deserves to be investigated further because, of all the isoenzymes, CYP2D6 is known to have substantial interindividual variation. ${ }^{45}$

\section{CYP3A4}

The evidence for the degree of CYP3A4 involvement in paracetamol metabolism in humans remains mixed. An in vitro study suggested that human CYP3A4 contributes $1 \%-20 \%$ of total metabolism, especially at lower doses; despite being a substrate, paracetamol also appeared to inhibit its activity. ${ }^{39}$ However, a subsequent in vitro study showed that CYP3A4 inhibition did not affect NAPQI formation. ${ }^{44}$ A more recent in vitro study using human recombinant cytochromes suggested that bioactivation of paracetamol at both therapeutic $50 \mu \mathrm{M}$ and toxic $1 \mathrm{mM}$ concentrations is largely due to CYP3A4, ahead of CYP1A2, CYP2A6, CYP2B6, CYP2C9, CYP2C19, CYP2D6, and CYP2E1. ${ }^{43}$ This study has been criticized for the lack of cytochrome b5 in the model, which may have resulted in suppression of CYP2E1 activity. ${ }^{46}$ Mice humanized for CYP3A4 show enhanced paracetamol-induced hepatotoxicity following overdose. ${ }^{47}$ However, two separate human volunteer studies using therapeutic paracetamol doses failed to show any enhancement of NAPQI formation following CYP3A4 induction with either rifampicin or carbamazepine. ${ }^{36,48}$ Overall, it appears that the contribution of CYP3A4 to paracetamol metabolism and NAPQI formation in humans is likely to be limited.

\section{CYP2EI}

CYP2E1 is widely considered to be the main isoenzyme responsible for NAPQI formation. Human CYP2E1 has been shown in vitro to contribute to $30 \%-78 \%$ of paracetamol metabolism. ${ }^{38}$ In vitro inhibition of CYP2E1 also significantly reduces the amount of NAPQI produced. ${ }^{44}$ Compared with CYP2A6, CYP2E1-mediated oxidative metabolism produces NAPQI preferentially (as opposed to 3-OH-acetaminophen, which is a nontoxic metabolite produced by CYP2A6), and CYP2E1 is the more efficient isoenzyme at toxic doses of paracetamol. ${ }^{35}$ Studies in mice show that CYP2E1 is equally efficient for NAPQI production at both low and higher doses of paracetamol, ${ }^{40} \mathrm{CYP} 2 \mathrm{E} 1$-null mice experience less hepatotoxicity compared with wild-type mice for comparable doses of paracetamol, ${ }^{49}$ and double knockout mice for CYP2E1 and CYP1A2 are protected against both hepatotoxicity and glutathione depletion despite massive paracetamol overdose. ${ }^{37}$ In human volunteers given a therapeutic paracetamol dose, CYP2E1 suppression with disulfiram pretreatment resulted in significantly less NAPQI production. ${ }^{36}$

\section{Evidence for increased hepatotoxicity via altered paracetamol metabolism}

There are a number of pharmacological agents that induce the CYP isoenzymes involved in paracetamol metabolism. These include carbamazepine, phenobarbital, phenytoin, primidone, rifampicin, rifabutin, efavirenz, nevirapine, and St John's wort. ${ }^{13}$ Currently in the UK, therapeutic use of these medications is considered a "high-risk" factor for paracetamolrelated hepatotoxicity, and patients are treated using the 100 line rather than the 200 line. We will now review the evidence on whether therapeutic use of and/or concurrent exposure to these drugs is actually likely to put patients at higher risk of paracetamol-related hepatotoxicity.

\section{Phenobarbital}

Coadministration of phenobarbital and paracetamol has been linked with enhanced toxicity in vitro, in animal models, and in humans, although this toxicity may be the result of suppressed 
glucuronidation rather than CYP induction. ${ }^{18,21,23,50-59}$ Paracetamol-poisoned rats and mice show enhanced hepatotoxicity when pretreated with phenobarbital, in association with either normal or increased recovery of cysteine and mercapturic conjugates. ${ }^{17,21,54}$ In rats, phenobarbital appears to accelerate the onset of hepatotoxicity ( 24 versus 72 hours) rather than worsen the overall degree of hepatonecrosis. ${ }^{54}$ In another rat model, coadministration of phenobarbital $150 \mathrm{mg} / \mathrm{kg}$ one hour before paracetamol $400 \mathrm{mg} / \mathrm{kg}$ suppressed glucuronidation, and this correlated with hepatotoxicity; the speed at which this interaction occurred suggests the increased hepatotoxicity was not a result of CYP induction..$^{56}$ Furthermore, in vitro studies in human hepatocyte cultures show that phenobarbital only induces CYP2B6 and CYP3A4 but not the more relevant CYP2E1..$^{52,53,60,61}$ In vitro studies in human hepatocyte cultures also show that coadministration (but not pretreatment) of phenobarbital suppresses glucuronidation, with reduced uridine $5^{\prime}$-diphosphate-glucuronosyltransferase, in particular the UGT1A6, UGT1A9, and UGT2B19 isoenzymes, and this correlates with toxicity. ${ }^{50,51}$ A single, controlled, crossover, volunteer study reported that coadministration of subtoxic phenobarbital and paracetamol doses resulted in increased recovery of mercapturic and cysteine conjugates, indicating increased production of NAPQI. ${ }^{23}$ These reports suggest that phenobarbital suppresses paracetamol glucuronidation, resulting in a larger burden of paracetamol diverted to NAPQI production, and that this effect is without relevant CYP induction. However, there is little clinical evidence for enhanced hepatotoxicity after paracetamol overdose in phenobarbital-treated patients. Published case reports involve unreliable histories. One reported a patient with an undisclosed ingestion of phenobarbital preceding an overdose of $11 \mathrm{~g}$ paracetamol, whilst another patient had ingested therapeutic doses on a long-term basis before the onset of hepatotoxicity, and the case description does not exclude the possibility of undisclosed repeated supratherapeutic paracetamol ingestion. ${ }^{58,62}$ There are no case series or controlled clinical trials looking at the effect of phenobarbital treatment alone prior to paracetamol overdose or of phenobarbital-paracetamol coingestion. In a retrospective study of patients with fulminant hepatic failure, 18 paracetamol-poisoned patients on antiepileptic therapy (five receiving phenobarbital) were reported to have significantly "worse" hepatotoxicity compared with an historical unmatched series of patients not receiving antiepileptic drugs. However, the antiepileptic medications cannot be clearly implicated, because these patients presented more than 8 hours after paracetamol ingestion and were not treated with $\mathrm{N}$-acetylcysteine. ${ }^{59}$
In summary, whilst there are limited data in patients with paracetamol poisoning, from in vitro, animal, and human volunteer studies, it appears that phenobarbital predominantly increases the risk of paracetamol poisoning by reduction of glucuronidation and resultant increased metabolism to NAPQI, rather than by CYP isoenzyme induction. Potentially, it is not just patients who are taking phenobarbital therapeutically who are at risk but also patients who coingest phenobarbital with paracetamol in overdose.

\section{Phenytoin}

As well as CYP3A4 induction, phenytoin may also affect paracetamol glucuronidation. In vitro, phenytoin induces human CYP3A4 up to two-fold, but reduces paracetamol glucuronidation by 50\%.50,51,61 However, in vivo, phenytointreated volunteers receiving a therapeutic dose of paracetamol have increased urinary glucuronide conjugates compared with controls, alongside either reduced or unchanged mercapturic and cysteine conjugates, which suggests phenytoin should not enhance paracetamol-induced hepatotoxicity by a reduction in glucuronidation. ${ }^{48,63}$ Although there are anecdotal reports of more severe hepatotoxicity, these are not reliable, because they describe phenytoin-treated patients with substantial paracetamol overdoses over $12 \mathrm{~g}$ and either delayed or unreliable times of ingestion. Suchin et al reported a phenytointreated patient ingesting an overdose of paracetamol $25 \mathrm{~g}$, who presented with established hepatotoxicity; the reported plasma paracetamol concentration and clinical course suggests an undisclosed delayed presentation. ${ }^{64,65}$ Minton et al reported on another phenytoin-treated patient who developed hepatotoxicity following paracetamol poisoning. In this case, $\mathrm{N}$-acetylcysteine was withheld because the timed plasma paracetamol concentration was below the 200 line, but the patient would have qualified for therapy based on the 150 line. ${ }^{57} \mathrm{McClements}$ et al reported on another phenytointreated patient who presented over 24 hours after ingestion of $45 \mathrm{~g}$ of paracetamol and died after treatment with cimetidine (instead of $\mathrm{N}$-acetylcysteine). ${ }^{66}$ The study that is most often quoted to support antiepileptic medication as a risk factor for paracetamol toxicity is an uncontrolled study of 18 patients on antiepileptic medications (seven on phenytoin, either as monotherapy or part of combination therapy) who had significantly worse hepatotoxicity compared with patients not on antiepileptic treatment. ${ }^{59}$ However, the patients presented late (median time to presentation was 14 hours), eight did not have any detectable serum paracetamol, 15 did not receive $\mathrm{N}$-acetylcysteine, and the comparison was with a historical series of unmatched control patients. Therefore, we feel it 
is not possible to determine that the hepatotoxicity was due to the antiepileptic drugs rather than other factors. Overall, insufficient data exist to determine whether paracetamolinduced hepatotoxicity might be more common or more severe in patients normally receiving phenytoin.

\section{Primidone}

Primidone is metabolized into phenobarbital in vivo. ${ }^{67}$ In a small limited study, the pharmacokinetics of $1000 \mathrm{mg}$ oral and intravenous paracetamol in six epileptic patients on long-term treatment with various combinations of primidone, phenobarbital, phenytoin, and carbamazepine was compared with six nonepileptic controls. ${ }^{68}$ The number treated with primidone was not documented. Following the oral paracetamol dose, reduced bioavailability but without altered urinary excretion was noted in the patients on antiepileptics, leading the authors to conclude that antiepileptic medications enhanced hepatic first-pass metabolism of paracetamol. The effect of primidone alone cannot be discerned from this study. There are no specific studies addressing the interaction between paracetamol and primidone alone. However, we would anticipate that because primidone is a prodrug of phenobarbital, the risks would be similar to phenobarbital, whereby it increases risk of paracetamol-related hepatotoxicity by reducing glucuronidation, and therefore results in an increase in metabolism of paracetamol to NAPQI.

\section{Carbamazepine}

Carbamazepine induces human CYP3A4 in vitro and in vivo. ${ }^{48,61}$ There are no data to suggest that carbamazepine induces CYP2E1 or alters glucuronidation/sulfation of paracetamol. In a controlled human volunteer study, the urinary excretion of paracetamol metabolites was no different between carbamazepine-treated epileptics and carbamazepine-naïve healthy controls, demonstrating that NAPQI production is not affected by carbamazepine. ${ }^{48}$ No convincing data exist to examine the impact of normal therapeutic use of carbamazepine on risk of hepatotoxicity after paracetamol overdose.

\section{Rifampicin}

In vitro, rifampicin is a human CYP3A4 and CYP2D6 inducer. ${ }^{52,61}$ When administered to mice humanized for both the pregnane $\mathrm{X}$ receptor and CYP3A4, rifampicin is associated with worsened paracetamol-induced hepatotoxicity. ${ }^{47}$ However, in a human volunteer study, pretreatment with rifampicin enhanced CYP3A4 activity without increasing the production of NAPQI following a subtherapeutic
$500 \mathrm{mg}$ paracetamol dose. ${ }^{36}$ There are no data to suggest that rifampicin induces CYP2E1 or alters glucuronidation/ sulfation of paracetamol. Furthermore, there are no published cases associating rifampicin alone with worsened paracetamol-induced hepatotoxicity.

\section{Rifabutin, efavirenz, nevirapine}

These agents are also CYP3A4 inducers, ${ }^{52,69,70}$ but there are no in vitro, animal, or human studies to demonstrate that therapeutic use of these drugs is associated with increased formation of NAPQI. There are no data to suggest that these drugs induce CYP2E1 or alter glucuronidation/sulfation of paracetamol.

\section{St John's wort}

In human volunteer studies, St John's wort has been shown to induce significant CYP3A4 activity. ${ }^{71-74}$ There is also a report of CYP2E1 induction by St John's wort in human volunteers. ${ }^{71}$ However, there are no reports of an interaction between St John's wort and paracetamol, either therapeutically or following overdose.

\section{Isoniazid}

Isoniazid, a hepatotoxic drug in its own right, ligand-stabilizes CYP2E1, which means binding initially inhibits CYP2E1 before inducing it. ${ }^{75}$ This process is reflected in controlled human volunteer studies that show initial NAPQI formation is reduced before being enhanced. In one study of 10 slow acetylators (patients with slower isoniazid metabolism due to $\mathrm{N}$-acetyltransferase phenotype) pretreated with isoniazid for 7 days, a $500 \mathrm{mg}$ paracetamol dose resulted in $49 \%-63 \%$ less NAPQI formation during isoniazid treatment compared with 3 days after cessation of isoniazid. ${ }^{76}$ In another study, concurrent isoniazid and paracetamol doses resulted in 57\% less NAPQI formation, but a paracetamol dose 12 hours after the isoniazid dose resulted in significantly more NAPQI formation in fast acetylators compared with slow acetylators. ${ }^{77}$ There are no data to suggest that isoniazid alters the glucuronidation/sulfation of paracetamol. On the basis of the currently available literature, it is not possible to be conclusive as to the potential for isoniazid to increase the risk of hepatotoxicity following paracetamol overdose. We would advise that, given the potential for therapeutic isoniazid use to induce CYP2E1, those taking isoniazid who present with paracetamol overdose should be treated as "high-risk". It is unclear as to whether ingestion of isoniazid in a nonchronic user could theoretically reduce the risk of paracetamol-related hepatotoxicity by inhibiting paracetamol metabolism via 
CYP2E1 to NAPQI, meaning that this individual would then be "normal-risk" rather than "high-risk". However, because there is no conclusive evidence to be able to determine the time at which CYP2E1 induction occurs relative to the time of isoniazid ingestion, we feel that to reduce confusion and potential harm to the individual, concurrent or recent single ingestion of isoniazid in relation to paracetamol should be considered a "high-risk" factor for paracetamol-related hepatotoxicity.

\section{Conclusion}

The current literature suggests that the CYP isoenzyme responsible for the majority of human biotransformation of paracetamol to NAPQI is CYP2E1 at both therapeutic and toxic doses of paracetamol. The contribution of other isoenzymes, such as CYP1A2, CYP2D6, and particularly CYP3A4 at toxic doses, is unclear, but appears to be minimal.

Current UK guidelines suggest that patients who use a number of drugs therapeutically should be treated as "high-risk" after paracetamol overdose. However, based on our review of the available literature, it appears that the only drugs for which there is the potential for an increased risk are phenobarbital, primidone, isoniazid, and perhaps St John's wort. For phenobarbital, and its precursor primidone, the predominant mechanism for this increased risk appears to be inhibition of glucuronidation, leading to a greater proportion of paracetamol being available for metabolism to NAPQI. Both therapeutic use of phenobarbital and concurrent ingestion of phenobarbital in paracetamol overdose would appear to increase risk. There appears to be no evidence that phenobarbital increases NAPQI formation due to CYP2E1 induction. For isoniazid the evidence is conflicting, although there is the potential that it is an inducer of CYP2E1, and therefore therapeutic use of isoniazid may increase NAPQI formation and therefore the risk of paracetamol toxicity. St John's wort is implicated based on a single human volunteer study. ${ }^{71}$ However, there is no evidence that other drugs often quoted as increasing risk, such as carbamazepine, phenytoin, primidone, rifampicin, rifabutin, efavirenz, or nevirapine, are inducers of CYP2E1 or alter glucuronidation/sulfation of paracetamol substantially. Therefore, in our opinion, therapeutic use of these drugs or concurrent ingestion in overdose with paracetamol should not be considered a risk factor for paracetamol-related hepatotoxicity.

\section{Disclosure}

The authors report no conflicts of interest in this work.

\section{References}

1. Davidson DG, Eastham WN. Acute liver necrosis following overdose of paracetamol. Br Med J. 1966;2(5512):497-499.

2. Thomson JS, Prescott LF. Liver damage and impaired glucose tolerance after paracetamol overdosage. Br Med J. 1966;2(5512):506-507.

3. Gow PJ, Smallwood RA, Angus PW. Paracetamol overdose in a liver transplantation centre: an 8-year experience. J Gastroenterol Hepatol. 1999;14(8):817-821.

4. Brandsaeter B, Hockerstedt K, Friman S, et al. Fulminant hepatic failure: outcome after listing for highly urgent liver transplantation-12 years experience in the nordic countries. Liver Transpl. 2002;8(11):1055-1062.

5. Tessier G, Villeneuve E, Villeneuve JP. Etiology and outcome of acute liver failure: experience from a liver transplantation centre in Montreal. Can J Gastroenterol. 2002;16(10):672-676.

6. Larson AM, Polson J, Fontana RJ, et al. Acetaminophen-induced acute liver failure: results of a United States multicenter, prospective study. Hepatology. 2005;42(6):1364-1372.

7. Bernal W, Cross TJ, Auzinger G, et al. Outcome after wait-listing for emergency liver transplantation in acute liver failure: a single centre experience. J Hepatol. 2009;50(2):306-313.

8. Clemmesen JO, Ott P, Dalhoff KP, Astrup LB, Tage-Jensen U, Poulsen HE. Recommendations for treatment of paracetamol poisoning Danish Medical Society, Study of the Liver. Ugeskr Laeger. 1996;158(48):6892-6895.

9. Wallace CI, Dargan PI, Jones AL. Paracetamol overdose: an evidence based flowchart to guide management. Emerg Med J. 2002;19(3): 202-205.

10. Brok J, Buckley N, Gluud C. Interventions for paracetamol (acetaminophen) overdose. Cochrane Database Syst Rev. 2006;2: CD003328.

11. Wolf SJ, Heard K, Sloan EP, Jagoda AS; American College of Emergency Physicians. Clinical policy: critical issues in the management of patients presenting to the emergency department with acetaminophen overdose. Ann Emerg Med. 2007;50(3):292-313.

12. Daly FF, Fountain JS, Murray L, Graudins A, Buckley NA. Guidelines for the management of paracetamol poisoning in Australia and New Zealand - explanation and elaboration. A consensus statement from clinical toxicologists consulting to the Australasian poisons information centres. Med J Aust. 2008;188(5):296-301.

13. NPIS. TOXBASE: The primary clinical toxicological database of the National Poisons Information Service. National Poisons Information Service; cited April 8, 2011; Available from: http://www.toxbase.org/ Poisons-Index-A-Z/P-Products/Paracetamol------------/.

14. Vale JA, Proudfoot AT. Paracetamol (acetaminophen) poisoning. Lancet. 1995;346(8974):547-552.

15. Waring WS, Robinson OD, Stephen AF, Dow MA, Pettie JM. Does the patient history predict hepatotoxicity after acute paracetamol overdose? QJM. 2008;101(2):121-125.

16. Buckley NA, Whyte IM, O'Connell DL, Dawson AH. Activated charcoal reduces the need for $\mathrm{N}$-acetylcysteine treatment after acetaminophen (paracetamol) overdose. J Toxicol Clin Toxicol. 1999;37(6):753-757.

17. Mitchell JR, Jollow DJ, Potter WZ, Davis DC, Gillette JR, Brodie BB. Acetaminophen-induced hepatic necrosis. I. Role of drug metabolism. J Pharmacol Exp Ther. 1973;187(1):185-194.

18. Potter WZ, Davis DC, Mitchell JR, Jollow DJ, Gillette JR, Brodie BB. Acetaminophen-induced hepatic necrosis. 3. Cytochrome P-450-mediated covalent binding in vitro. J Pharmacol Exp Ther. 1973;187(1):203-210.

19. Corcoran GB, Mitchell JR, Vaishnav YN, Horning EC. Evidence that acetaminophen and N-hydroxyacetaminophen form a common arylating intermediate, N-acetyl-p-benzoquinoneimine. Mol Pharmacol. 1980;18(3):536-542.

20. Dahlin DC, Nelson SD. Synthesis, decomposition kinetics, and preliminary toxicological studies of pure $\mathrm{N}$-acetyl-p-benzoquinone imine, a proposed toxic metabolite of acetaminophen. J Med Chem. 1982;25(8):885-886. 
21. Mitchell JR, Jollow DJ, Potter WZ, Gillette JR, Brodie BB. Acetaminophen-induced hepatic necrosis. IV. Protective role of glutathione. J Pharmacol Exp Ther. 1973;187(1):211-217.

22. Jollow DJ, Thorgeirsson SS, Potter WZ, Hashimoto M, Mitchell JR. Acetaminophen-induced hepatic necrosis. VI. Metabolic disposition of toxic and nontoxic doses of acetaminophen. Pharmacology. 1974;12(4-5):251-271.

23. Mitchell JR, Thorgeirsson SS, Potter WZ, Jollow DJ, Keiser H. Acetaminophen-induced hepatic injury: protective role of glutathione in man and rationale for therapy. Clin Pharmacol Ther. 1974;16(4):676-684.

24. Potter WZ, Thorgeirsson SS, Jollow DJ, Mitchell JR. Acetaminopheninduced hepatic necrosis. V. Correlation of hepatic necrosis, covalent binding and glutathione depletion in hamsters. Pharmacology. 1974;12(3):129-143.

25. Prescott LF, Roscoe P, Wright N, Brown SS. Plasma-paracetamol half-life and hepatic necrosis in patients with paracetamol overdosage. Lancet. 1971;1(7698):519-522.

26. Rumack BH, Matthew H. Acetaminophen poisoning and toxicity. Pediatrics. 1975;55(6):871-876.

27. Lee WM. Review article: drug-induced hepatotoxicity. Aliment Pharmacol Ther. 1993;7(5):477-485.

28. Ostapowicz G, Fontana RJ, Schiodt FV, et al. Results of a prospective study of acute liver failure at 17 tertiary care centers in the United States. Ann Intern Med. 2002;137(12):947-954.

29. Hamlyn AN, James OF, Lesna M, Roberts SH, Watson AJ, Douglas AP. Proceedings: Liver function tests and histology in survivors of acute paracetamol (acetaminophen) poisoning. Gut. 1975;16(10):838.

30. James O, Lesna M, Roberts SH, et al. Liver damage after paracetamol overdose. Comparison of liver-function tests, fasting serum bile acids, and liver histology. Lancet. 1975;2(7935):579-581.

31. Prescott LF. Paracetamol overdosage. Pharmacological considerations and clinical management. Drugs. 1983;25(3):290-314.

32. O'Grady JG, Alexander GJ, Hayllar KM, Williams R. Early indicators of prognosis in fulminant hepatic failure. Gastroenterology. 1989;97(2):439-445.

33. Harrison PM, O'Grady JG, Keays RT, Alexander GJ, Williams R. Serial prothrombin time as prognostic indicator in paracetamol induced fulminant hepatic failure. BMJ. 1990;301(6758):964-966.

34. Dahlin DC, Miwa GT, Lu AY, Nelson SD. N-acetyl-p-benzoquinone imine: a cytochrome P-450-mediated oxidation product of acetaminophen. Proc Natl Acad Sci U S A. 1984;81(5):1327-1331.

35. Chen W, Koenigs LL, Thompson SJ, et al. Oxidation of acetaminophen to its toxic quinone imine and nontoxic catechol metabolites by baculovirus-expressed and purified human cytochromes P450 2E1 and 2A6. Chem Res Toxicol. 1998;11(4):295-301.

36. Manyike PT, Kharasch ED, Kalhorn TF, Slattery JT. Contribution of CYP2E1 and CYP3A to acetaminophen reactive metabolite formation. Clin Pharmacol Ther. 2000;67(3):275-282.

37. Zaher H, Buters JT, Ward JM, et al. Protection against acetaminophen toxicity in CYP1A2 and CYP2E1 double-null mice. Toxicol Appl Pharmacol. 1998;152(1):193-199.

38. Raucy JL, Lasker JM, Lieber CS, Black M. Acetaminophen activation by human liver cytochromes P450IIE1 and P450IA2. Arch Biochem Biophys. 1989;271(2):270-283.

39. Thummel KE, Lee CA, Kunze KL, Nelson SD, Slattery JT. Oxidation of acetaminophen to N-acetyl-p-aminobenzoquinone imine by human CYP3A4. Biochem Pharmacol. 1993;45(8):1563-1569.

40. Snawder JE, Roe AL, Benson RW, Roberts DW. Loss of CYP2E1 and CYP1A2 activity as a function of acetaminophen dose: relation to toxicity. Biochem Biophys Res Commun. 1994;203(1):532-539.

41. Sarich T, Kalhorn T, Magee S, et al. The effect of omeprazole pretreatment on acetaminophen metabolism in rapid and slow metabolizers of S-mephenytoin. Clin Pharmacol Ther. 1997;62(1):21-28.

42. Dong H, Haining RL, Thummel KE, Rettie AE, Nelson SD. Involvement of human cytochrome P450 2D6 in the bioactivation of acetaminophen. Drug Metab Dispos. 2000;28(12):1397-1400.
43. Laine JE, Auriola S, Pasanen M, Juvonen RO. Acetaminophen bioactivation by human cytochrome $\mathrm{P} 450$ enzymes and animal microsomes. Xenobiotica. 2009:39(1):11-21.

44. Hazai E, Vereczkey L, Monostory K. Reduction of toxic metabolite formation of acetaminophen. Biochem Biophys Res Commun. 2002;291(4):1089-1094.

45. De Gregori M, Allegri M, De Gregori S, et al. How and why to screen for CYP2D6 interindividual variability in patients under pharmacological treatments. Curr Drug Metab. 2010;11(3):276-282.

46. Zhao L, Pickering G. Paracetamol metabolism and related genetic differences. Drug Metab Rev. 2011;43(1):41-52.

47. Cheng J, Ma X, Krausz KW, Idle JR, Gonzalez FJ. Rifampicin-activated human pregnane $\mathrm{X}$ receptor and CYP3A4 induction enhance acetaminophen-induced toxicity. Drug Metab Dispos. 2009;37(8): $1611-1621$.

48. Tomlinson B, Young RP, Ng MC, Anderson PJ, Kay R, Critchley JA. Selective liver enzyme induction by carbamazepine and phenytoin in Chinese epileptics. Eur J Clin Pharmacol. 1996;50(5):411-415.

49. Wolf KK, Wood SG, Allard JL, et al. Role of CYP3A and CYP2E1 in alcohol-mediated increases in acetaminophen hepatotoxicity: comparison of wild-type and Cyp2e1(-/-) mice. Drug Metab Dispos. 2007;35(7):1223-1231.

50. Kostrubsky SE, Sinclair JF, Strom SC, et al. Phenobarbital and phenytoin increased acetaminophen hepatotoxicity due to inhibition of UDP-glucuronosyltransferases in cultured human hepatocytes. Toxicol Sci. 2005;87(1):146-155.

51. Mutlib AE, Goosen TC, Bauman JN, Williams JA, Kulkarni S, Kostrubsky S. Kinetics of acetaminophen glucuronidation by UDPglucuronosyltransferases 1A1, 1A6, 1A9 and 2B15. Potential implications in acetaminophen-induced hepatotoxicity. Chem Res Toxicol. 2006;19(5):701-709.

52. Hariparsad N, Nallani SC, Sane RS, Buckley DJ, Buckley AR, Desai PB. Induction of CYP3A4 by efavirenz in primary human hepatocytes: comparison with rifampin and phenobarbital. J Clin Pharmacol. 2004;44(11):1273-1281.

53. Zhang JG, Ho T, Callendrello AL, Crespi CL, Stresser DM. A multiendpoint evaluation of cytochrome P450 1A2, 2B6 and 3A4 induction response in human hepatocyte cultures after treatment with beta-naphthoflavone, phenobarbital and rifampicin. Drug Metab Lett. 2010;4(4):185-194.

54. Poulsen HE, Lerche A, Pedersen NT. Phenobarbital induction does not potentiate hepatotoxicity but accelerates liver cell necrosis from acetaminophen overdose in the rat. Pharmacology. 1985;30(2):100-108.

55. Blouin RA, Dickson P, McNamara PJ, Cibull M, McClain C. Phenobarbital induction and acetaminophen hepatotoxicity: resistance in the obese Zucker rodent. J Pharmacol Exp Ther. 1987;243(2): $565-570$.

56. Douidar SM, Ahmed AE. A novel mechanism for the enhancement of acetaminophen hepatotoxicity by phenobarbital. $J$ Pharmacol Exp Ther. 1987;240(2):578-583.

57. Minton NA, Henry JA, Frankel RJ. Fatal paracetamol poisoning in an epileptic. Hum Toxicol. 1988;7(1):33-34.

58. Pirotte JH. Apparent potentiation of hepatotoxicity from small doses of acetaminophen by phenobarbital. Ann Intern Med. 1984;101(3):403.

59. Bray GP, Harrison PM, O'Grady JG, Tredger JM, Williams R. Longterm anticonvulsant therapy worsens outcome in paracetamol-induced fulminant hepatic failure. Hum Exp Toxicol. 1992;11(4):265-270.

60. Edwards RJ, Price RJ, Watts PS, et al. Induction of cytochrome P450 enzymes in cultured precision-cut human liver slices. Drug Metab Dispos. 2003;31(3):282-288.

61. Luo G, Cunningham M, Kim S, et al. CYP3A4 induction by drugs: correlation between a pregnane $\mathrm{X}$ receptor reporter gene assay and CYP3A4 expression in human hepatocytes. Drug Metab Dispos. 2002;30(7):795-804.

62. Lystbaek BB, Norregaard P. A case of paracetamol retard poisoning with fatal outcome. Ugeskr Laeger. 1995;157(7):899-900. 
63. Prescott LF, Critchley JA, Balali-Mood M, Pentland B. Effects of microsomal enzyme induction on paracetamol metabolism in man. $\mathrm{BrJ}$ Clin Pharmacol. 1981;12(2):149-153.

64. Suchin SM, Wolf DC, Lee Y, et al. Potentiation of acetaminophen hepatotoxicity by phenytoin, leading to liver transplantation. Dig Dis Sci. 2005;50(10):1836-1838.

65. Cook MD, Williams SR, Clark RF. Phenytoin-potentiated hepatotoxicity following acetaminophen overdose? A closer look. Dig Dis Sci. 2007;52(1):208-209.

66. McClements BM, Hyland M, Callender ME, Blair TL. Management of paracetamol poisoning complicated by enzyme induction due to alcohol or drugs. Lancet. 1990;335(8704):1526.

67. Bogan J, Smith H. The relation between primidone and phenobarbitone blood levels. J Pharm Pharmacol. 1968;20(1):64-67.

68. Perucca E, Richens A. Paracetamol disposition in normal subjects and in patients treated with antiepileptic drugs. Br J Clin Pharmacol. 1979;7(2):201-206.

69. Trapnell CB, Jamis-Dow C, Klecker RW, Collins JM. Metabolism of rifabutin and its 25-desacetyl metabolite, LM565, by human liver microsomes and recombinant human cytochrome P-450 3A4: relevance to clinical interaction with fluconazole. Antimicrob Agents Chemother. 1997;41(5):924-926.

70. Lamson MJ, Sabo JP, MacGregor TR, et al. Single dose pharmacokinetics and bioavailability of nevirapine in healthy volunteers. Biopharm Drug Dispos. 1999;20(6):285-291.
71. Gurley BJ, Gardner SF, Hubbard MA, et al. Cytochrome P450 phenotypic ratios for predicting herb-drug interactions in humans. Clin Pharmacol Ther. 2002;72(3):276-287.

72. Markowitz JS, Donovan JL, DeVane CL, et al. Effect of St John's wort on drug metabolism by induction of cytochrome P450 3A4 enzyme. JAMA. 2003;290(11):1500-1504.

73. Wang Z, Gorski JC, Hamman MA, Huang SM, Lesko LJ, Hall SD. The effects of St John's wort (Hypericum perforatum) on human cytochrome P450 activity. Clin Pharmacol Ther. 2001;70(4):317-326.

74. Wenk M, Todesco L, Krahenbuhl S. Effect of St John's wort on the activities of CYP1A2, CYP3A4, CYP2D6, N-acetyltransferase 2, and xanthine oxidase in healthy males and females. Br J Clin Pharmacol. 2004;57(4):495-499.

75. Chien JY, Thummel KE, Slattery JT. Pharmacokinetic consequences of induction of CYP2E1 by ligand stabilization. Drug Metab Dispos. 1997;25(10):1165-1175.

76. Zand R, Nelson SD, Slattery JT, et al. Inhibition and induction of cytochrome P4502E1-catalyzed oxidation by isoniazid in humans. Clin Pharmacol Ther. 1993;54(2):142-149.

77. Chien JY, Peter RM, Nolan CM, et al. Influence of polymorphic $\mathrm{N}$-acetyltransferase phenotype on the inhibition and induction of acetaminophen bioactivation with long-term isoniazid. Clin Pharmacol Ther. 1997;61(1):24-34.
Open Access Emergency Medicine

\section{Publish your work in this journal}

Open Access Emergency Medicine is an international, peer-reviewed, open access journal publishing original research, reports, editorials, reviews and commentaries on all aspects of emergency medicine. The manuscript management system is completely online and includes a very quick and fair peer-review system, which is all easy to use.

\section{Dovepress}

Visit http://www.dovepress.com/testimonials.php to read real quotes from published authors. 